\title{
CONTROVERSIAS
}




\section{LA SOCIOLOGIA: CRISIS Y DESAFIOS}

\section{Jorge Orlando Melo*}

En esta corta intervención trataré de ofrecer la impresión que me produce la actividad académica de los sociólogos, desde mi experiencia como historiador. Me apoyaré en esta última disciplina para formular las cuestiones centrales del desarrollo del país.

1. La identidad de la disciplina. Lo primero que quiero señalar es cierta pérdida de identidad gremial de la práctica académica de los sociólogos. Yo trabajo en el Instituto de Estudios Políticos y Relaciones Internacionales de la Universidad Nacional, y si miro las hojas de vida de mis compañeros, descubro que hay cinco o seis sociólogos. No lo había advertido: no hay casi nada en su lenguaje profesional, en su metodología, que me permita identificarlos en forma excluyente con lo que, cuando era un estudiante universitario, se identificaba con un sociólogo. El único, quizás, es Alejandro Reyes, con su amplio trabajo de campo, su ordenamiento sistemático y clasificatorio de la información y su apelación a teorías de la acción social. Fals fue, en la primera mitad del ochenta, más bien un historiador, y lo que los lectores identificaban como sociólogo era la parte menos aceptada de sus libros dobles. A los demás los siento como ensayistas políticos (William Ramírez), o en una encrucijada multidisciplinaria (Francisco Leal o Eduardo Pizarro, entre científicos políticos e historiadores contemporáneos).

A poca distancia, el Departamento de Sociología parecería un poco más cerca a un modelo profesional, pero tampoco logro definirlo con claridad: ¿qué tiene de diferente al trabajo de un historiador la historia política de Hesper Pérez o los estudios de historia de la cultura de Carlos Uribe Celis, o de historia del trabajo y de la formación profesional de Mayor? En Mayor identifico por lo menos junto con los aportes y virtudes que da a la historia una conceptualización de origen sociológico, algunos rasgos de los que nos sirven para crear el estereotipo de los sociólogos: los cuadros porcentuales basados en universos reducidos, las generalizaciones sobre una base empírica discutible, la preferencia por la explicación abstracta sobre el esfuerzo por mostrar la compleja trabazón de hilos que configura un proceso histórico concreto.

Me siento más cómodo con mis prejuicios sobre lo que es la sociología como disciplina cuando veo los que siguen trabajando sobre diversos aspectos particulares 0 sectoriales de la sociedad actual, en particular en áreas no competidas por los antropólogos (la cultura popular, la familia, las minorías étnicas) o por los politólogos. Creo identificar grupos relativamente activos que estudian las colonizaciones (Darío Fajardo, Jaime Eduardo Jaramillo, Alfredo Molano), el trabajo femenino (Magdalena León, Elsy Bonilla) la educación (Gonzalo Cataño y Rodrigo Parra) y la violencia urbana (Alvaro Camacho y Alvaro Guzmán). Quizá todavía existen dos o tres demógrafos activos, rama que puede ser una disciplina sociológica. Unos pocos trabajan sobre sindicatos y conflictos obreros, pero el tema parece no tener muchos practicantes.

Ambos sectores, los que parecen haber desdibujado su identidad para trabajar en los vértices de la interdisciplinariedad, como los que siguen fieles a un modelo profesional

\footnotetext{
*Historiador. Actual asesor presidencial para la defensa de los Derechos Humanos. Intervención en la mesa redonda convocada por la Asociación Colombiana de Sociología sobre "El estado de la sociología en Colombia". (Bogotá, mayo 18 de 1990).
} 
más estricto, constituyen ese mundo de la sociología colombiana vinculado a la universidad y al debate científico público, y en ambos grupos veo virtudes irrenunciables.

Al lado de estos sociólogos, que son los que leo y por lo tanto, de los que puedo hablar con algo de familiaridad, existe, me parece, una inmensa actividad profesional que desconozco pero que presumo de gran valor, sobre todo empírico: en muchas entidades oficiales los sociólogos elaboran diagnósticos e informes que raras veces se divulgan y cuyos materiales no entran en el flujo académico, aunque podrían ayudar a engrosar su caudal.

2. Los temas que mencioné antes me parecen válidos y por supuesto, quisiera mucha más investigación acerca de ellos. Pero me produce la sensación de que existe una compartimentalización del trabajo sociológico, que hace que exista muy poca confrontacion entre las explicaciones que dan los autores de determinados fenómenos. Las afirmaciones se vuelven verdades poco discutibles. Y de cada fenómeno (y una obvia razón es el tamaño todavía reducido de la comunidad científica), se estudian apenas uno o dos aspectos: hacen falta, por ejemplo, los estudios sociológicos que complementarían los aportes de Camacho y Guzmán estudiando la policía —su cultura, su inserción social, sus valores-, o el sistema judicial, o grupos violentos específicos, aunque dudo que algunos temas de estos puedan trabajarse sin riesgos excesivos, o los estudios sobre nuestra cultura de masas, los mensajes de los medios de comunicación, la televisión, la radio, el impacto de la prensa. ¿Se ha hecho en la última década algún estudio concreto y sistemático sobre la evolución de la estructura social o de clases en el país o en alguna región? ¿O sobre la vida privada —ocio, cambios en el comportamiento sexual, violencia intrafamiliar-? ¿O en un nivel más amplio, sobre las grandes transformaciones culturales que ha tenido el país en los últimos treinta años? ¿O sobre las culturas regionales o la imbricación de culturas campesinas y urbanas en las grandes ciudades? ¿O sobre las redes del poder en Colombia, hay algo después de los esbozos de Camacho de hace ya más de una década? ¿Dónde se reclutan los poderosos, como se relacionan, qué papel tienen colegios, clubes, universidades, cofradías, roscas o barras? ¿Cuál es la estructura del poder en nuestro país, al menos donde esto es relativamente definible (empresarios, intelectuales, políticos)? En un país tan clientelista, ¿qué sabemos sobre cómo opera el clientelismo?

Me sorprende también el reducido debate teórico. Esto es común a áreas como la historia, donde poco se produce en este terreno. Pero al menos entre los historiadores hay cuatro o cinco temas favoritos de discusión: el grado de feudalismo del siglo XIX, el sentido de la regeneración, el impacto de la crisis mundial sobre el desarrollo industrial, el papel de la inflación en el desarrollo cafetero, el carácter de la Revolución en Marcha, etc.: allí, por lo menos, se hace el ejercicio de enfrentar, por parte de dos o tres autores, hipótesis relativamente contrapuestas. ¿Cuáles son los debates explícitos de los sociólogos colombianos? ¿Cuáles son las discusiones teóricas? Pues no constituyen discusión teórica los artículos divulgativos sobre algún concepto de Marx o Max Weber. En general, me parece que los sociólogos y el pecado es común a los historiadores, han hecho una especie de pacto de no agresión mutua, que se manifiesta en una crítica muy tibia y poco comprometida de los trabajos de los colegas. Se reconoce a todos el derecho a trabajar su tema, se le respeta el enfoque metodológico que han adoptado y, colocados en su nicho, se elogian sus aportes y contribuciones. A veces parecería que las divergencias de orientación se desplazaran hacia aspectos más prosaicos y se expresan a través de otras clases de enfrentamientos, de conflictos burocráticos o institucionales, en los que las divergencias conceptuales se mantienen implícitas. 
3. Esto me remite a un proceso que creo se ha dado en las disciplinas que tratan de comprender la realidad colombiana. Durante la década del sesenta se formó buena parte del equipo profesional que todavía hoy constituye el núcleo más productivo de la investigación social en Colombia. El contexto político y cultural favoreció una aproximación a los problemas que trataba de combinar cierto grado de conocimiento empírico con un proyecto político que exigía inscribir los estudios dentro de una perspectiva teórica global, que para la mayoría fue el marxismo. Simplificando la situación, durante los setentas se produjo una exacerbación de la teoría, que terminó colocándose por encima de la realidad: las teorías favoritas fueron aquellas que permitieron calificar como empirista o positivista la mayoría de las metodologías con las que la historia o la sociología se enfrentaban a la realidad del país, las que discutían incluso la existencia de nada que pudiera denominarse "realidad". Es posible que todo esto tuviera que ver con la crisis del proyecto socialista, que se fue haciendo cada vez más remoto y menos fácil de justificar conceptualmente. No quedaba otra cosa que defender la acción por la acción y negarse a reconocer la magnitud de los cambios que se estaban dando en Colombia y que contradecían los supuestos admitidos hasta entonces.

La historia que conduce al renacimiento de un trabajo en cierto sentido más tradicional en las ciencias sociales tiene demasiados elementos para intentar resumirlos en esta breve intervención. El hecho es, en todo caso, que en la última década recuperaron legitimidad académica las investigaciones empíricas, y se fue reconstituyendo un ambiente académico normal. Ahora bien, mi impresión es que estamos a punto de movernos en forma excesiva hacia el otro extremo, en un movimiento pendular que tiende a reemplazar la "gran teoría" más o menos vacía por la renuncia a toda forma de teoría. También en este caso los factores culturales y políticos internacionales tienen su influencia, en forma tan obvia que no hace falta detallar. No sé si la situación es tan radical en los nuevos sociólogos como parece serlo en las más recientes generaciones de historiadores. Los estudiantes avanzados, en este momento, parecen haber renunciado a todo esfuerzo de unificación teórica, a todo intento de explicaciones globales. Las críticas "posmodernistas" a la teoría, aún si no son conocidas en sus formulaciones sistemáticas, se han convertido en parte del ambiente académico.

Esto puede conducir a una fragmentación del discurso académico, a una compartimentalización extrema en la que cualquier metodología es válida, frente a los múltiples e irreductibles discursos que pueden hacerse alrededor de cada tema. En una charla reciente, refiriéndome a la historia, señalé que al menos la magnitud de los problemas contemporáneos de Colombia podía servir para tener un punto de fuga en el que de alguna manera convirgieran los esfuerzos de interpretación del pasado. En historia esto es, sin embargo, algo voluntarista, a la luz de todas las críticas, difícilmente refutables, a los peligros de definir los problemas del pasado a la luz del presente.

En sociología, por el contrario, hay dos elementos, estrechamente relacionados, que hacen parte de la lógica de la disciplina que sirven para tratar de mantener la trabazón de los discursos y el esfuerzo por buscar perspectivas integradoras. El primero es por supuesto la contemporaneidad del objeto. El segundo, es e] de la demanda de esfuerzos de explicación global de procesos en los que es fácil plantear interrelaciones muy estrechas. Cualquier esfuerzo de explicación de temas como la violencia remite inmediatamente a problemas culturales, políticos, económicos. Cualquier problema vivido como central sugiere la necesidad de esfuerzos de visiones de conjunto.

Lo anterior es un esbozo de argumento para sostener que en mi opinión valdría la pena que sociólogos y científicos sociales trataran de volver en cierto sentido a la teoría. 
Ya no a la "gran teoría", al discurso conceptual deductivo. Pero si a esfuerzos de elaborar teorías apoyadas en un creciente saber empírico, que intenten generar proposiciones sintéticas sobre nuestra sociedad. Ya lo sabemos: no habrá "una" teoría ni un gran sistema conceptual. Pero me parece que hay que tratar de balancear la tendencia a abandonar todos los debates teóricos, pues sigo convencido de que sin teoría, explícita o implícita, se empiezan a trivializar las preguntas y problemas que tratamos de resolver y se genera una fragmentación del discurso científico que suprime, de algún modo, el espacio del debate y del diálogo racional.

Quizás el debate de la modernidad y la posmodernidad, que ha surgido en otros países y tiende a convertirse en una moda más o menos frívola, pueda convertirse, si se le toma con seriedad y disciplina, en un tema que obligue a una reflexión de fondo sobre los rasgos centrales de la sociedad colombiana actual. Porque ante la magnitud de las transformaciones que ha sufrido el país, surgen toda clase de preguntas, y estamos todavía muy lejos de empezar a formular las hipótesis básicas que nos permitan intentar responderlas. Y para hacer preguntas y formular hipótesis, la teoría sigue siendo esencial, así sepamos ya que ella sola da muy pocas respuestas. 